\title{
DNA methylation and socioeconomic status in a Mexican-American birth cohort
}

\author{
Eric S. Coker ${ }^{1,2^{*}}$, Robert Gunier ${ }^{1,2}$, Karen Huen ${ }^{1,3}$, Nina Holland ${ }^{1,3}$ and Brenda Eskenazi ${ }^{1,2}$
}

\begin{abstract}
Background: Maternal social environmental stressors during pregnancy are associated with adverse birth and child developmental outcomes, and epigenetics has been proposed as a possible mechanism for such relationships.

Methods: In a Mexican-American birth cohort of 241 maternal-infant pairs, cord blood samples were measured for repeat element DNA methylation (LINE-1 and Alu). Linear mixed effects regression was used to model associations between indicators of the social environment (low household income and education, neighborhood-level characteristics) and repeat element methylation. Results from a dietary questionnaire were also used to assess the interaction between maternal diet quality and the social environment on markers of repeat element DNA methylation.

Results: After adjusting for confounders, living in the most impoverished neighborhoods was associated with higher cord blood LINE-1 methylation ( $\beta=0.78,95 \% \mathrm{Cl} 0.06,1.50, p=0.03$ ). No other neighborhood-, household-, or individual-level socioeconomic indicators were significantly associated with repeat element methylation. We observed a statistical trend showing that positive association between neighborhood poverty and LINE-1 methylation was strongest in cord blood of infants whose mothers reported better diet quality during pregnancy $\left(p_{\text {interaction }}=0.12\right)$.

Conclusion: Our findings indicate a small yet unexpected positive association between neighborhood-level poverty during pregnancy and methylation of repetitive element DNA in infant cord blood and that this association is possibly modified by diet quality during pregnancy. However, our null findings for other adverse SES indicators do not provide strong evidence for an adverse association between early-life socioeconomic environment and repeat element DNA methylation in infants.
\end{abstract}

Keywords: Diet, Epigenetics, Methylation, Repeat element, Social adversity, Socioeconomic status

\section{Background}

Social disadvantage in early-life can adversely affect child development as evidenced by the higher rates of preterm birth and low birth weight, asthma, and poorer cognitive function of children from economically impoverished families and neighborhoods [1-10]. While the precise mechanisms by which social disadvantage affects child health is not fully understood, it has been hypothesized that maternal exposure to social stressors during pregnancy, such as poverty, may alter the offspring's epigenome [11, 12].

DNA methylation, which is the attachment of methyl groups primarily at $\mathrm{CpG}$ sites, is an example of an epigenetic modification that can regulate gene expression [13,

\footnotetext{
* Correspondence: escoker@gmail.com

${ }^{1}$ Center for Environmental Research and Children's Health (CERCH), School of Public Health, University of California, Berkeley, CA, USA

Berkeley, USA

Full list of author information is available at the end of the article
}

14], with methylation of repetitive elements being one commonly studied epigenetic marker. Repetitive elements make up approximately half of the human genome and include retrotransposable elements like long and short interspersed nuclear elements (LINEs and SINEs, respectively). Of the LINEs and SINES, the LINE-1 and Alu elements are the most abundant, together representing nearly a third of the human genome [15]. Although previously referred to as markers of global methylation, recent studies have demonstrated that LINE-1 and Alu methylation do not correlate well with global genomic methylation content $[16,17]$, are not correlated with each other $[18,19]$, and each represents distinct and important components of the epigenome $[17,20]$.

In the present study, we focus on perinatal LINE-1 and Alu methylation related to the maternal socioeconomic environment because previous epidemiological 
studies suggest associations with social and environmental stressors on LINE-1 and Alu methylation in both children and in adults. Both human and animal studies indicate hypomethylation or high copy numbers of LINE-1 or SINE elements in relation to stress or psychiatric disorders [21-25]. DNA methylation of LINE-1 and Alu elements have also been associated with environmental pollutant exposures (both hypomethylation and hypermethylation) [26-31], diet and nutrition [32-34], and other lifestyle factors [31, 35]. These relationships may have biological relevance since hypomethylation of repetitive elements may affect genomic instability and later disease states [36, 37].

Few studies have examined the relationships between early-life socioeconomic disadvantage and methylation in newborn blood or placental tissue. A birth cohort study conducted in New York [38] found no association between maternal education during pregnancy and global DNA methylation measured by immunoassay in infant cord blood, while another study in Rhode Island found maternal socioeconomic disadvantage, including lower education level, to be related to placental hypomethylation of the HSD11B2 gene (that may affect maternal cortisol exposure in the infant) [39]. Meanwhile, a birth cohort study from North Carolina found that lower maternal education and household income were associated with hypomethylation of IGF2 and H19 imprinted genes but there was no association with other genes (MEG3 and NNAT) [40]. In a separate analysis in this same North Carolina cohort, authors observed an opposite and significant association with neighborhood socioeconomic status (SES) for MEG3 (hypermethylation) [41]. Finally, a birth cohort study from China [42] measured DNA methylation at several hundred CpG sites and found that lower maternal SES was associated with older epigenetic age using a novel 'epigenetic clock' method. However, repeat element methylation in infants has yet to be examined in relation to socioeconomic status.

Maternal nutrition may be an important co-exposure to consider in the context of socioeconomic disadvantage because neighborhood food environments and poverty level [43-45], and maternal socioeconomic status and nutrition [46-48] have been associated with each other. In addition, prenatal nutrition is associated with changes in DNA methylation [32, 33, 49, 50]. For example, prospective studies have found that supplementation with methyl donors during pregnancy, such as folate, was associated with hypermethylation of LINE-1elements in cord and maternal blood [34, 49, 51]. In a Dutch population, epigenetic changes (hyper- or hypo methylation depending on the gene) have been observed with prenatal famine exposure in a time of great social stress (World War II) and these changes have been retained into adulthood along with modifications of the imprinted genes that were preserved for several generations of offspring $[52,53]$. Thus, it appears plausible that good maternal diet during pregnancy may protect against the adverse effects of social adversity on the newborn epigenome.

In our study, we used a multi-level analysis to investigate associations between indicators of maternal socioeconomic status and DNA methylation of LINE-1 and Alu repeat elements in cord blood of infants who participated in the Center for Health Assessment of Mothers and Children of Salinas (CHAMACOS), a birth cohort study of predominantly economically disadvantaged Mexican-American farmworker families. We hypothesized that maternal socioeconomic status (SES) at the individual, household, and neighborhood level will influence the newborn epigenome as measured by LINE- 1 and Alu repeat elements and that maternal diet quality will modify this association.

\section{Methods \\ Study population}

Pregnant women were recruited from six community health clinics in the Salinas Valley, California (19992000) and were eligible for the CHAMACOS study if they were at least 18 years of age, less than 20 weeks gestation, spoke Spanish or English, were eligible for low income health insurance, and were planning to deliver at the local public hospital. There were 601 women enrolled of whom 526 delivered a live singleton infant. Cord blood samples were collected at the time of delivery, of which 241 had sufficient DNA to analyze methylation of LINE-1 and Alu repeats and cell composition estimates. There were no significant differences in sociodemographic characteristics or important health behaviors (e.g., smoking) between the mothers of children who were included and those who were not included in these analyses (data not shown).

\section{Socioeconomic disadvantage and maternal diet during pregnancy}

Women were interviewed to collect individual- and household-level indicators of SES and other demographic information (e.g., age and race). Maternal interviews occurred twice during pregnancy at $\sim 13$ and $\sim 26$ weeks gestation, and all interviews were administered in English or Spanish by trained bilingual interviewers.

\section{Individual- and household-level variables}

We obtained information on maternal education and household income, and the number of people living in the home at the first interview. Mother's education was constructed into three categories ( $\leq 6$ th grade, $7-12$ th grade, and $\geq$ high school), while household poverty income ratio variables were classified into quartiles for analysis. Household poverty income ratio was computed by combining information on the reported household income and the 
number of people supported by that income and then dividing these values by the year 2000 US Census poverty threshold values for the number of people living in the household [54]. Hence, a poverty income ratio $<1$ entails that the household is below the poverty line and conversely a poverty income ratio $\geq 1$ entails that the household is above the poverty line.

\section{Neighborhood-level variables}

Census tract data were obtained for the year 2000 from the US Census Bureau. We examined sociodemographic measures for the census tract the woman lived in including: percent of homes below the poverty line, median household income, and percent of people that completed high school within census tracts. Each neighborhood SES variable was categorized into quartiles for analysis.

\section{Dietary intake during pregnancy}

Information regarding dietary and nutritional supplement intake were ascertained at the second prenatal interview ( $\sim 26$ weeks gestation) [54]. Briefly, we used a validated 72-item food-frequency questionnaire (FFQ) that was developed for Spanish-speaking populations $[55,56]$. The FFQ collected information on typical food intake such as frequency and portion sizes for specific food items. We converted food and vitamin supplement intake into average daily energy and nutrient intake as set out by United States Department of Agriculture Nutrient Database for Standard Reference [57]. With data from the FFQ, we determined maternal diet quality, using the Diet Quality Index for Pregnancy (DQI-P) [58]. The original DQI-P comprises eight different components of dietary intake; however, we had data for seven of these components (we were not able to include the component for the number of meals and snacks per day). The seven components assessed the adequacy of intake grains, fruits, and vegetables; the intake of fat as a proportion of all energy intake; and the adequacy of specific nutrient intake of folate, iron, and calcium. A higher DQI-P score is indicative of better diet quality while a lower score is indicative of poorer diet quality. For greater details on how these data were collected and DQI- $P$ values were derived, see Harley et al. 2006 [54].

\section{DNA methylation in cord blood}

Umbilical cord blood samples were collected at the delivery room. Samples were centrifuged and divided into serum and clot and stored at $-80^{\circ} \mathrm{C}$ [59]. DNA were isolated from clots with a QIAamp Blood DNA Maxi kit (Qiagen, Inc., Santa Clarita, CA, USA) (further details described in Holland et al. 2006) [59]. For bisulfite conversion of $500 \mathrm{ng}$ of DNA, we used EpiTect Bisulfite Conversion Kits (Qiagen, Germantown, MD, USA). Bisulfite converted samples were then eluted into $20 \mu \mathrm{L}$ Elution buffer. To confirm complete bisulfite conversion, we calculated the proportion of cytosine at the first non-CpG site, considering proportions over $7 \%$ as an indicator of incomplete bisulfite conversion. Cytosine proportions for the non-CpG site in individual samples reflective of incomplete bisulfite conversion ranged from 0.1 to $4.2 \%$ (mean $=1.5 \%$ ), confirming excellent conversion efficiency for the majority of samples (99\%) [26]. Pyrosequencing of PCR-amplified and bisulfite-treated DNA samples was used to determine LINE-1 and Alu methylation levels, using the Pyromark Q96MD System (Qiagen). Methylation of LINE-1 and Alu (\%5-mC [\%5-methylated cytosine]) was calculated at each of the four known $\mathrm{CpG}$ sites and for each triplicate analysis of each participant sample using Pyro Q-CpG Software (Qiagen) [60, 61]. Details of bisulfite pyrosequencing of Alu and LINE-1 methylation have been described by previous studies $[60,62]$.

A combination of QA/QC approaches was used to reduce technical and batch sources of variability. We included a no template control (NTC) in addition to unmethylated, partially methylated, and completely methylated genomic DNA. Intraplate repeats of samples were also randomly distributed across plates. We ran all sample plates on the same day in order to limit batch variability. All coefficients of variation for repeat measures and intraplate coefficients of variation were in acceptable ranges $(\leq 5 \%)$ [26], and all isolated DNA samples had 260/280 ratios $>1.6$.

\section{Covariates}

Covariates were selected for fully adjusted models based on the literature $[26,51,63-65]$ and a directed acyclic graph (DAG) (Additional file 1: Figure S1). For all models, confounders included maternal age at delivery, the number of years living in the USA ( $\leq 1$ year, $2-5$ years, $6-10$ years, 11-24 years, and entire life), maternal smoking during pregnancy, maternal diet quality during pregnancy (DQI-P) , and maternal urinary phthalate concentrations of monobenzyl phthalate $(\mathrm{MBz})$ during pregnancy. Maternal age was obtained during the baseline interview as was tobacco smoking status during pregnancy. In a previous work, we showed that prenatal exposure to urinary MBzP (a phthalate metabolite) was inversely associated with LINE-1 methylation [26] and that indicators of maternal SES were moderately to highly correlated with urinary MBzP [66]. Maternal urinary MBzP concentrations were determined for pregnancy by collecting maternal urine at each prenatal interview and measured by on-line solid phase extraction coupled with isotope dilution-high-performance liquid chromatography-electrospray ionization-tandem mass spectrometry at the Center for Disease Control and Prevention [67]. The two measurements were averaged to derive an overall pregnancy average concentration. We used logtransformed values of MBzP in the regression analyses. Cell composition was controlled for in sensitivity analyses. Cell composition estimation was performed using a recently 
validated reference database of nucleated cord blood cell types [68, 69]. Cell types included CD8T, CD4T, Natural killer, B lymphocytes, Monocytes, Granulocytes, and nucleated red blood cells.

\section{Statistical analysis}

Summary statistics were computed for all study covariates, exposures of interest, and basic study population characteristics. Linear mixed effects regression was used to detect associations between LINE-1 and Alu DNA methylation in cord blood and indicators of the social environment at the individual, household, and neighborhood levels, and for maternal diet quality during pregnancy (DQI-P). Continuous SES indicator variables (percent below poverty, median household income, percent with a high school education, and poverty income ratio) were modeled in separate analyses as continuous and in quartiles (to account for potential non-linearity). We then explored whether SES associations with repeat element methylation were modified by prenatal maternal diet quality. Consistent with our previous work [26, 27], we ran mixed effects models with a random effect for repeat analyses (triplicate) of DNA methylation to account for correlation within subject and a separate random effect for methylation sites (four CpG sites analyzed for both LINE-1 and Alu assays) to account for site-specific correlation. In our main analyses looking at socioeconomic indicators and diet quality, we implemented three separate mixed effects models. In model 1, we only controlled for random effects to estimate crude associations between exposures of interest and methylation. In model 2 we adjusted for maternal factors including smoking during pregnancy, age at delivery, MBzP urinary concentrations, and diet quality. Model 3 was a sensitivity analysis, where we adjusted for cell type estimates since methylation is likely to be dependent on cell type. Finally, to test for interaction between diet quality and measures of socioeconomic disadvantage, we applied interaction terms between each categorical socioeconomic indicator variable and DQI-P (diet quality, modeled continuous), adjusting for all other covariates in model 2. For illustrative purposes and to display interaction effects, we consider stratified analyses by DQI-P quintiles. All summary statistics and regression models were analyzed with $\mathrm{R}$ statistical software (version 3 . 2.4) using the lmer function (lmerTest, version 2.0-32) for linear mixed effects regression models. A $p$ value $<0.05$ and $<0.1$ were considered statistically significant and marginally significant, respectively, for main effects. Since there are simultaneous tests when assessing for interaction between a categorical variable (e.g., quantiles) and another variable, we applied a partial sum of squares $F$ test (anova command in $\mathrm{R}$ ) in order to report on $p$ values for the diet quality (significance-level at $p_{\text {interaction }}<0.05$ ). In addition to $p$ values, we also qualitatively assessed the heterogeneity in effect sizes when stratifying by quintiles of diet quality. In order to take advantage of the complete data on the study outcomes, missing values on the covariates included in the regression models were imputed using factorial analysis for mixed data on both continuous and categorical variables (R package: missMDA). The percent missing for the three imputed covariates were as follows: $<1 \%(N=1)$ on maternal MBzP concentration, $<1 \%(N=1)$ on maternal age, and $5 \%(N=13)$ on DQI-P.

\section{Results}

Maternal and infant characteristics included in our analysis are presented in Table 1. Newborns were evenly split between males $(49.8 \%)$ and females $(50.2 \%)$ with mean gestation length and birth weight of 39 weeks and $3467 \mathrm{~g}$, respectively. Most of the mothers were Latina (96\%) with an average maternal age at delivery of 26 years. Mean prepregnancy BMI was $26.5 \mathrm{~kg} / \mathrm{m}^{2}$, with the majority of mothers classified as either overweight (37\%) or obese (20\%) prior to pregnancy.

Individual-level socioeconomic disadvantage (Table 1) and household-level socioeconomic disadvantage (Table 2) was severe in the study population. A majority of mothers have less than a high school degree $(79 \%)$ and live in households with a poverty income ratio $<1$ (70\%). Neighborhood socioeconomic disadvantage was similarly high, with a tract-level median of $\$ 34,211$ for median household income and median percentages of $24 \%$ for household poverty and $73 \%$ without a high school education. Correlations between maternal- or household- and neighborhood-level socioeconomic class indicators were generally weak although mostly in the anticipated directions (Additional file 1: Figure S2). Of all the study covariates included in adjusted regression models, MBzP and the number of years living in the USA exhibited the strongest correlations with the SES variables of interest for this study $(r=-0.27$ to 0.30$)$. Maternal smoking was only weakly correlated with household-level poverty income ratio $(r=0.10)$ and income $(r=0.06)$, moderately correlated with the number of years living in the USA $(r=0.27)$, and moderately correlated with neighborhood SES (range $r=-0.23,0.22$ ).

\section{DNA methylation: LINE-1 and Alu}

Average LINE-1 methylation was 78.9 (\%5-mC) (95\%CI $78.7,79.1$ ). As much as $11 \%$ (chi-squared test $p$ value < 0.05 ) of the overall variance in LINE-1 methylation was explained by differences between CpG sites (suggesting significant level $2 \mathrm{CpG}$ site effects). LINE-1 methylation levels were also slightly higher in boys compared to girls $(p=0.03)$, marginally lower in low birth weight infants compared to normal weight infants $(p=0.06)$, but there was no association between preterm infants and LINE-1 methylation. The summary statistics for LINE-1 methylation, stratified by quantiles of the SES indicators, are 
Table 1 Summary statistics of participating infants and mothers, CHAMACOS ( $n=241$ mother-infant dyads)

\begin{tabular}{|c|c|}
\hline & All \\
\hline \multicolumn{2}{|l|}{ Infant } \\
\hline \multicolumn{2}{|l|}{ Preterm birth, $N(\%)$} \\
\hline Yes & $13(5.4)$ \\
\hline No & $228(94.6)$ \\
\hline \multicolumn{2}{|l|}{ Low birth weight, $N(\%)$} \\
\hline Yes & $7(2.9)$ \\
\hline No & $234(97.1)$ \\
\hline \multicolumn{2}{|l|}{ Mother } \\
\hline Age at pregnancy, years $(\mathrm{M} \pm \mathrm{SD})$ & $25.8 \pm 5.3$ \\
\hline Pre-pregnancy body mass index, $\mathrm{kg} / \mathrm{m}^{2}(\mathrm{M} \pm \mathrm{SD})$ & $26.5 \pm 5.0$ \\
\hline \multicolumn{2}{|l|}{ Race/ethnicity, N (\%) } \\
\hline Latino & $232(96.2)$ \\
\hline White & $5(2.1)$ \\
\hline Other & $4(1.7)$ \\
\hline \multicolumn{2}{|l|}{ Educational attainment, $N(\%)$} \\
\hline$<6$ th grade & $98(40.7)$ \\
\hline $7-12$ grade & $92(38.2)$ \\
\hline$\geq$ High school & $51(21.1)$ \\
\hline \multicolumn{2}{|l|}{ Country of birth, $N(\%)$} \\
\hline U.S. & $32(13.3)$ \\
\hline Mexico & $205(85.1)$ \\
\hline Central America/other & $4(1.7)$ \\
\hline \multicolumn{2}{|l|}{ Years spent living in the U.S., $N(\%)$} \\
\hline$<=1$ year & $61(25.3)$ \\
\hline $2-5$ years & $70(29.0)$ \\
\hline $6-10$ years & $48(19.9)$ \\
\hline $11-24$ years & $34(14.1)$ \\
\hline Entire life (18-32 years) & $28(11.6)$ \\
\hline Diet quality index during pregnancy $(\mathrm{M} \pm \mathrm{SD})$ & $44.90 \pm 9.66$ \\
\hline Urinary $M B z P^{a}, \mu g / L\left(I Q R^{b}\right)$ & $9.5(4.7,17.8)$ \\
\hline
\end{tabular}

${ }^{a}$ Median urinary concentration, limit of detection is $0.3 \mu \mathrm{g} / \mathrm{L}$

bIQR interquartile range

Table 2 Summary statistics of SES at the household and census tract level, CHAMACOS $(n=241)$

\begin{tabular}{ll}
\hline SES indicators & \\
\hline Household & Median (IQR) \\
Income, monthly (\$) & $375.2(281.4,562.8)$ \\
Poverty income ratio & $0.98(0.65,1.20)$ \\
Neighborhood (census tracts) & Median (IQR) \\
Household income, yearly (\$) & $34211(31910,41354)$ \\
$\%$ of household below poverty & $23.50(19.38,27.54)$ \\
$\%$ of people with no high school diploma & $72.80(50.10,75.34)$ \\
\hline
\end{tabular}

presented in Table 3. Average Alu methylation was 25.3 (\%5-mC) (95\%CI 25.1, 25.5) and clustering of methylation levels by $\mathrm{CpG}$ site. There were no significant differences in Alu methylation levels between boys and girls or by preterm or low birth weight of the infant. Confirming our previous work, maternal urinary $\mathrm{MBzP}$ consistently resulted in a statistically significant linear negative association with LINE-1 methylation (model 2). Interestingly, fewer years spent living in the USA ( $\leq 1$ year and 2-5 years) consistently had significantly higher LINE-1 methylation compared to those who lived their entire life in the USA.

\section{Associations of SES and DNA methylation}

The summary statistics for LINE-1 methylation, stratified by the different SES categories, are presented in Additional file 1: Table S1. There were no significant differences in LINE-1 methylation by neighborhood income levels or by neighborhood educational attainment, in both crude (model 1) and adjusted (model 2) analyses (Table 4). Living in the highest poverty neighborhood quartile was significantly associated with higher LINE-1 methylation compared to living in the lowest poverty neighborhood quartile (adjusted $\beta=0.78,95 \% \mathrm{CI}: 0.06,1.50, p=0.03$ ). There was a lack of a linear trend $(p=0.51)$ for increasing neighborhood poverty quartiles and methylation. We found no statistically significant differences in LINE-1 methylation by individual- or household-level SES (Table 4) in crude or adjusted models. Although after adjustment, the second household income quartile and second poverty income ratio quartile were marginally associated with higher methylation compared to the highest SES quartile categories ( $p$-value $=0.05$ and 0.06 , respectively). After controlling for estimated cell type proportions (Model 3, Table 4), the neighborhood-level poverty association with LINE-1 methylation strengthened slightly $(\beta=0.88$, $p=0.02$ ), but the household-level SES variables attenuated substantially and were no longer marginally associated after controlling for cell type proportions. No significant associations of socioeconomic indicators were observed with Alu methylation (Additional file 1: Table S1).

\section{Diet quality during pregnancy, SES, and LINE-1}

\section{methylation}

Diet quality index during pregnancy (DQI-P) was positively, albeit non-significantly, associated with LINE-1 methylation in crude and adjusted models ( $p_{\text {adjusted }}=0.19$ ) (Table 4). Including an interaction term between neighborhood poverty quartiles and DQI-P indicated a statistical trend towards interaction $\left(p_{\text {interaction }}=0.12\right)$. In Fig. 1a, we present the adjusted regression coefficients for each poverty quartiles on LINE-1 methylation when the regression analyses are stratified by DQI-P quintiles. We observed that in the highest quintile of DQI-P 
Table 3 Mean LINE-1\% methylation overall and stratified by SES indicator categories and years living in the USA

\begin{tabular}{|c|c|}
\hline SES indicators & LINE-1\% mean methylation ( $95 \% \mathrm{Cl})$ \\
\hline Overall & $78.9(78.7,79.1)$ \\
\hline \multicolumn{2}{|l|}{ Maternal-level } \\
\hline \multicolumn{2}{|l|}{ Educational attainment } \\
\hline$<6$ th grade & $78.8(78.5,79.1)$ \\
\hline 7th-12th grade & $79.2(78.8,79.4)$ \\
\hline$\geq$ High school & $78.7(78.3,79.2)$ \\
\hline \multicolumn{2}{|l|}{ Household-level } \\
\hline \multicolumn{2}{|l|}{ Monthly income quartiles } \\
\hline 1st quartile (\$37-\$225) & $78.7(78.3,79.2)$ \\
\hline 2nd quartile (\$281-\$375) & $79.1(78.8,79.4)$ \\
\hline 3rd quartile (\$438-\$563) & $78.8(78.4,79.2)$ \\
\hline 4th quartile $(\$ 583-\$ 1750)$ & $78.7(78.1,79.2)$ \\
\hline \multicolumn{2}{|l|}{ Poverty income ratio quartiles } \\
\hline 1st quartile (0.13-0.65) & $78.8(78.4,79.2)$ \\
\hline 2nd quartile (0.71-0.98) & $79.1(78.8,79.5)$ \\
\hline 3rd quartile (1.01-1.21) & $78.9(78.8,79.3)$ \\
\hline 4th quartile $(1.30-2.40)$ & $78.7(78.2,79.1)$ \\
\hline \multicolumn{2}{|l|}{ Neighborhood (census tract)-level } \\
\hline \multicolumn{2}{|l|}{ Median household income quartiles } \\
\hline 1st quartile $(\$ 24,896-\$ 31910)$ & $78.9(78.6,79.2)$ \\
\hline 2nd quartile $(\$ 31,989-\$ 34593)$ & $78.7(78.2,79.2)$ \\
\hline 3rd quartile $(\$ 34,848-\$ 40856)$ & $78.9(78.5,79.4)$ \\
\hline 4th quartile $(\$ 41,354-\$ 77272)$ & $79.0(78.6,79.4)$ \\
\hline \multicolumn{2}{|l|}{ Percent below poverty quartiles } \\
\hline 1st quartile (2.8-18.2) & $78.7(78.3,79.1)$ \\
\hline 2nd quartile (19.0-22.3) & $79.0(78.6,79.4)$ \\
\hline 3rd quartile (23.5-27.5) & $78.7(78.4,79.0)$ \\
\hline 4th quartile (27.7-34.2) & $79.8(79.1,80.4)$ \\
\hline \multicolumn{2}{|c|}{ Percent without a highschool education quartiles } \\
\hline 1st quartile (13.7-50.1) & $78.9(78.5,79.3)$ \\
\hline 2nd quartile (51.4-71.4) & $79.1(78.7,79.5)$ \\
\hline 3rd quartile (72.5-75.3) & $78.6(78.2,79.0)$ \\
\hline 4th quartile (78.7-87.0) & $78.9(78.6,79.3)$ \\
\hline \multicolumn{2}{|c|}{ Years living in the USA ("acculturation") } \\
\hline$<=1$ year & $79.2(78.6,79.7)$ \\
\hline $2-5$ years & $79.3(78.9,79.8)$ \\
\hline $6-10$ years & $78.8(78.4,79.8)$ \\
\hline $11-24$ years & $78.8(78.4,79.2)$ \\
\hline Entire life (18-32 years) & $78.4(77.8,78.9)$ \\
\hline
\end{tabular}

(best diet quality), the adjusted mean LINE-1 methylation was higher by $2.6 \%$ in the highest quartile of neighborhood poverty compared with the lowest poverty quartile. Conversely, in the lower DQI-P quintiles (poorer diet quality), there was either no differences in LINE-1 methylation or lower methylation with increasing neighborhood poverty quartiles compared to the lowest poverty quartile. When neighborhood poverty is modeled as a continuous variable along with an interaction term with DQI-P, this statistical trend strengthened $\left(p_{\text {interaction }}=0.06\right)$. As shown in Fig. 1b, at very low levels of maternal diet quality, there is a negative exposure-response relationship between neighborhood poverty and LINE-1 methylation, and conversely, at high levels of maternal diet quality, there is a positive exposure-response relationship between neighborhood poverty and LINE-1 methylation. In Fig. 1c, the relationship between neighborhood poverty and LINE-1 methylation is significant only at very high levels of maternal diet quality. There was no evidence for interaction between other indicators of SES and diet quality on LINE-1 methylation ( $p_{\text {interaction }}>0.2$ in all cases). Finally, we did not observe any differences in Alu methylation by diet (Additional file 1: Table S2) or by combination of diet and SES indicators ( $p_{\text {interaction }}>0.2$ in all cases).

\section{Discussion}

In the CHAMACOS cohort, we observed a small but statistically significant association between the prenatal socioeconomic environment and DNA methylation of LINE-1 repeat elements in infant cord blood. Specifically, only higher neighborhood poverty was significantly associated with LINE-1 hypermethylation and this association was possibly moderated by the quality of maternal diet during pregnancy.

As already discussed in the introduction, previous studies relating to epigenetic markers with maternal SES or neighborhood SES indicators during pregnancy vary by methodology, design, and findings. For instance, a cohort study in NY that examined the relationship between maternal SES and global DNA methylation in infant cord blood found no associations [38]. Our findings also show a null association between maternal education and LINE1 methylation but a positive relationship with neighborhood poverty. The NY study, however, did not consider neighborhood SES indicators. Furthermore, they used a measure of global methylation measured by immunoassay while our pyrosequencing analysis presented here focused on repetitive element methylation that does not necessarily correlate with global methylation.

Prenatal neighborhood-level poverty and individuallevel poverty have each been associated with adverse developmental outcomes such as low birth weight and preterm birth [70]. In our study, we only observed an epigenetic association with neighborhood poverty. The precise mechanisms of neighborhood effects on health or epigenetic changes are not clear. Such neighborhood effects possibly result from the sustained and combined exposures to multiple adverse social and 
Table 4 Results from linear regression mixed effects (LMER) models of crude and adjusted associations between maternal, household, and neighborhood indicators of SES and diet quality index and LINE-1 DNA methylation

\begin{tabular}{|c|c|c|c|c|c|c|}
\hline \multirow[t]{2}{*}{ Socioeconomic status indicators } & \multicolumn{2}{|l|}{ Model $1^{a}$} & \multicolumn{2}{|l|}{ Model $2^{b}$} & \multicolumn{2}{|l|}{ Model $3^{c}$} \\
\hline & $\beta(95 \% \mathrm{Cl})$ & $p$ value & $a \beta(95 \% C l)$ & $p$ value & $a \beta(95 \% C l)$ & $p$ value \\
\hline \multicolumn{7}{|l|}{ Household income } \\
\hline 1st quartile $(\$ 37-\$ 225)$ & $0.05(-0.59,0.70)$ & 0.88 & $0.08(-0.59,0.75)$ & 0.82 & $-0.18(-0.87,0.52)$ & 0.62 \\
\hline 2nd quartile $(\$ 281-\$ 375)$ & $0.46(-0.13,1.04)$ & 0.12 & $0.60(-0.01,1.21)$ & 0.05 & $0.18(-0.48,0.83)$ & 0.60 \\
\hline 3rd quartile (\$438-\$563) & $0.14(-0.52,0.80)$ & 0.68 & $0.20(-0.46,0.86)$ & 0.56 & $-0.07(-0.75,0.60)$ & 0.84 \\
\hline 4th quartile $(\$ 583-\$ 1750)$ & Reference & & Reference & & Reference & \\
\hline \multicolumn{7}{|l|}{ Household poverty income ratio } \\
\hline 1st quartile (0.13-0.65) & $0.07(-0.49,0.63)$ & 0.80 & $0.12(-0.45,0.69)$ & 0.68 & $-0.18(-0.78,0.41)$ & 0.54 \\
\hline 2nd quartile (0.71-0.98) & $0.08(-0.12,1.01)$ & 0.09 & $0.53(-0.03,1.08)$ & 0.07 & $0.15(-0.45,0.75)$ & 0.62 \\
\hline 3rd quartile (1.01-1.21) & $0.45(-0.42,0.82)$ & 0.56 & $0.21(-0.43,0.85)$ & 0.52 & $-0.13(-0.78,0.53)$ & 0.71 \\
\hline 4th quartile (1.30-2.40) & Reference & & Reference & & Reference & \\
\hline \multicolumn{7}{|l|}{ Maternal education } \\
\hline$<=6$ th grade & $0.04(-0.46,0.53)$ & 0.89 & $-0.09(-0.65,0.47)$ & 0.75 & $-0.03(-0.60,0.54)$ & 0.92 \\
\hline 7-12th grade & $0.39(-0.12,0.90)$ & 0.13 & $0.33(-0.20,0.86)$ & 0.22 & $0.35(-0.18,0.89)$ & 0.20 \\
\hline$>=$ Highschool & Reference & & Reference & & & \\
\hline \multicolumn{7}{|l|}{$\%$ Households below poverty (CT) } \\
\hline 1st quartile (2.8-18.2) & Reference & & Reference & & Reference & \\
\hline 2nd quartile (19.0-22.3) & $0.26(-0.27,0.80)$ & 0.34 & $0.24(-0.31,0.78)$ & 0.39 & $0.31(-0.26,0.85)$ & 0.30 \\
\hline 3rd quartile (23.5-27.5) & $-0.01(-0.49,0.47)$ & 0.97 & $-0.11(-0.61,0.39)$ & 0.68 & $-0.04(-0.47,0.54)$ & 0.89 \\
\hline 4th quartile (27.7-34.2) & $1.03(0.33,1.73)$ & 0.004 & $0.78(0.06,1.50)$ & 0.03 & $0.88(0.14,1.64)$ & 0.02 \\
\hline \multicolumn{7}{|l|}{ Median household income (CT) } \\
\hline 1st quartile $(\$ 24,896-\$ 31910)$ & $-0.05(-0.53,0.43)$ & 0.84 & $-0.03(-0.58,0.53)$ & 0.93 & $-0.02(-0.58,0.53)$ & 0.94 \\
\hline 2nd quartile (\$31,989-\$34593) & $-0.26(-0.84,0.32)$ & 0.39 & $-0.40(-0.93,0.13)$ & 0.14 & $-0.48(-1.01,0.05)$ & 0.08 \\
\hline 3rd quartile $(\$ 34,848-\$ 40856)$ & $0.02(-0.61,0.57)$ & 0.94 & $-0.12(-0.66,0.42)$ & 0.66 & $-0.01(-0.55,0.53)$ & 0.98 \\
\hline 4th quartile $(\$ 41,354-\$ 77272)$ & Reference & & Reference & & Reference & \\
\hline \multicolumn{7}{|l|}{ \% No highschool education (CT) } \\
\hline 1st quartile (13.7-50.1) & Reference & & Reference & & Reference & \\
\hline 2nd quartile (51.4-71.4) & $0.16(-0.38,0.70)$ & 0.55 & $0.07(-0.49,0.63)$ & 0.81 & $0.08(-0.48,0.64)$ & 0.77 \\
\hline 3rd quartile (72.5-75.3) & $-0.33(-0.84,0.19)$ & 0.21 & $-0.30(-0.84,0.24)$ & 0.28 & $-0.33(-0.87,0.22)$ & 0.24 \\
\hline 4th Quartile (78.7-87.0) & $-0.02(-0.50,0.54)$ & 0.94 & $-0.10(-0.66,0.46)$ & 0.72 & $0.04(-0.53,0.60)$ & 0.90 \\
\hline Diet quality index & $0.020(-0.008,0.032)$ & 0.24 & $0.13(-0.06,0.32)^{d}$ & 0.19 & $0.08(-0.12,0.27)^{d}$ & 0.44 \\
\hline
\end{tabular}

${ }^{a}$ Model 1: random effect for position and individual only

${ }^{\mathrm{b}}$ Model 2: random effect for position and individual, maternal smoking during pregnancy, maternal age, diet quality during pregnancy, years living in the USA for the mother, and prenatal MBzP exposure

'Model 3: random effect for position and individual, maternal smoking during pregnancy, maternal age, diet quality during pregnancy, years living in the USA for the mother, prenatal MBzP exposure, and cell estimate proportions

${ }^{d}$ Neighborhood poverty included as a covariate due to evidence of confounding by neighborhood poverty. Diet quality index was $Z$ standardized so that continuous variables were on similar scales

physical individual-level risk factors that may be experienced by individuals living in impoverished neighborhoods. The multiple social and physical risk factors can include low access to healthy foods [71] and health care, mental stress associated with violence and social isolation, higher exposure to environmental pollutants, and built environments that promote unhealthy behaviors [72]. Thus, one possible explanation behind our observing only neighborhood effects, rather than individual-level effects in our study, could be related to this concept of sustained and combined stressors tied to neighborhood SES, while a single parameter of individual socioeconomic adversity is unable to capture this accumulation of combined social, physical, and economic stressors. Additionally, our null findings for maternal-level and household-level socioeconomic indicators may be related to a relative homogeneity in low SES among the CHAMACOS participants. 


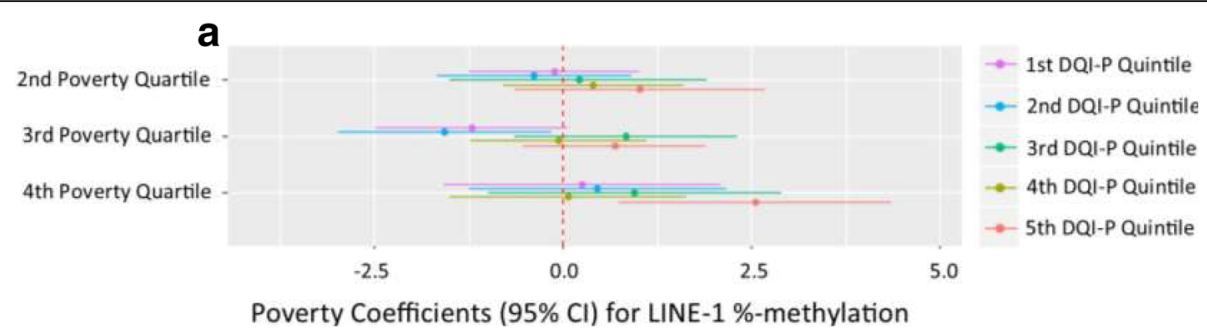

b
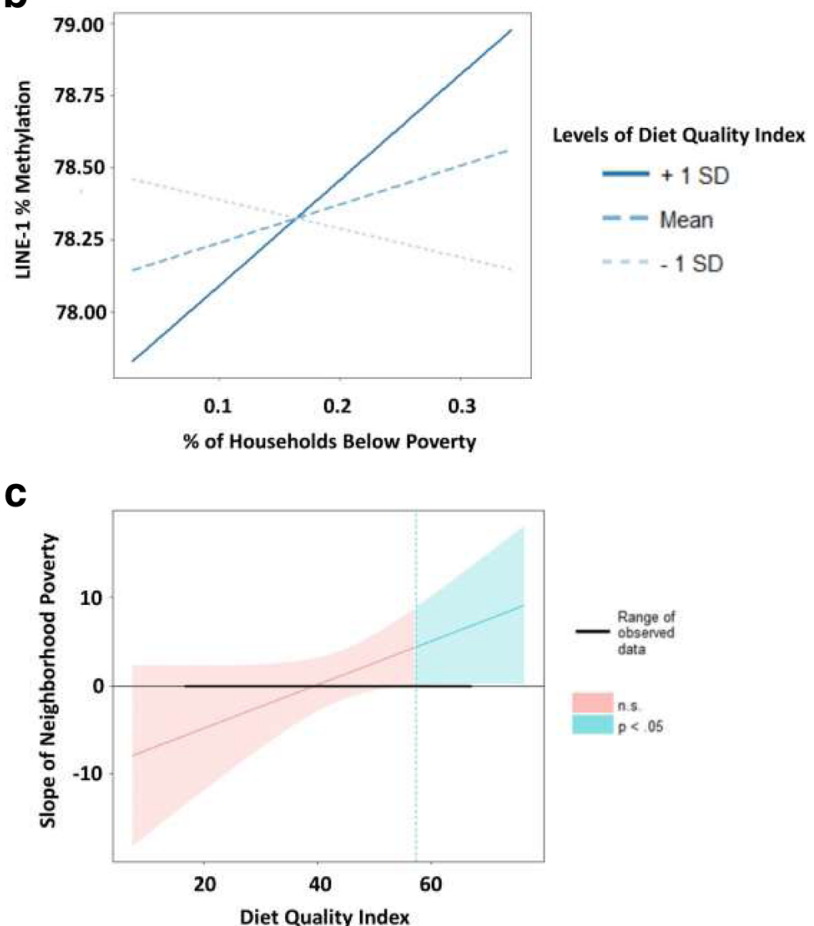

Fig. 1 Interaction between neighborhood poverty and maternal diet quality during pregnancy (DQI-P). a Displays the regression coefficients stratified by different quintiles of diet quality index (DQI-P). Regression coefficients are interpreted as the adjusted difference in LINE-1\%-methylation between a quartile of neighborhood poverty and the lowest neighborhood poverty quartile (reference). Each different color corresponds to a different stratum of DQI-P as indicated by the legend (e.g., purple is the first quintile of DQI-P and orange is the fifth quintile of DQI-P). $\mathbf{b}$ Displays the slopes for neighborhood poverty ( $x$ axis) on LINE-1\%-methylation (y axis) at different levels of DQI-P (e.g., dark blue line is the slope for observations at +1 standard deviation for DQI-P and the light gray line is the slope for observations at -1 standard deviation for DQI-P). c Displays the simple slopes for neighborhood poverty ( $(y$ axis) across different levels of DQI-P ( $x$ axis). The pink portion of the confidence interval indicates no statistical significance $(p>0.05)$ between poverty and LINE-1 methylation and the blue-green portion of the confidence interval indicates statistical significance $(p<0.05)$ between poverty and LINE-1 methylation. The vertical dotted line indicates the point at which the relationship between poverty and LINE-1 methylation becomes statistically significant

Since neighborhood poverty has typically been associated with greater exposure to maternal stress as well as adverse developmental outcomes in previous studies, it may appear counterintuitive that the children of CHAMACOS mothers living in higher poverty neighborhoods during pregnancy are observed to have higher LINE-1 methylation in cord blood, relative to lower poverty neighborhoods. Unexpected observation of protective social adversity effects in utero is not unfounded however. The prenatal LINE-1 hypermethylation observed in our study could reflect an adaptive response to maternal stress cues that is intended to influence the development of a phenotype that is adapted to coping with a similarly stressful environment later in life [73]. In other words, hypermethylation of LINE-1 may be a response to stress that could make the individual more resilient to similar stressful events in the future. For instance, the timing of elevated maternal anxiety during pregnancy and related prenatal exposure to higher levels of cortisol in utero has been shown to be protective of mental health and neurodevelopment in infancy [74], and newborn DNA methylation has been linked with infant cortisol response (glucocorticoid receptor gene methylation) [75] and infant neurodevelopment (LINE-1 methylation) [76]. A potential adaptive phenomenon with LINE-1 hypermethylation has also been reported in a military service personnel with post-traumatic stress disorder [21]. 
Further, a positive association between higher neighborhood poverty and LINE-1 methylation was primarily seen in the cord blood of infants from CHAMACOS mothers who had the highest quality dietary patterns during pregnancy (Fig. 1a). This finding of the potentially moderating epigenetic effects between neighborhood poverty and maternal diet quality lends some support to the hypothesis that maternal diet may supply "epi-nutrients" that influence epigenetic effects from exposure to stressors in utero [77]. In addition, other studies suggest that neighborhood poverty and nutrition, and their health effects, may be closely linked. Neighborhood-level disadvantage has been associated with poorer diet quality [78], poorer nutritional status [79], and higher hair cortisol levels (an indicator of chronic stress), while better diet among those with lower SES has been shown to be protective against inflammatory [80] and poor mental health outcomes [81, 82]. Future studies should measure maternal diet quality or nutritional status when considering neighborhood SES or maternal stress effects on infant epigenetics in order to assess the potential moderating role of maternal diet.

While no human studies have used a diet quality index to investigate associations with epigenetic changes, some researchers have investigated associations of specific nutrients as well as eating disorders during pregnancy in relation to repeat element methylation. One human study [65] found that choline intake during pregnancy was significantly and inversely related to cord blood LINE-1 methylation in boys but positively associated with LINE-1 methylation in girls (albeit non-significant). Another human study reported that folate supplementation was inversely related with cord blood LINE-1 methylation [51]. A recent study [83] found that maternal eating disorders (restrictive, purging, binge eating, binge-purge) during pregnancy were associated with hypomethylation in infant cord blood, possibly related to lower calorie intake. Our finding of a positive association (albeit statistically insignificant) between better diet quality during pregnancy and repeat element methylation also supports the role of maternal diet as a determinant of infant methylation levels.

Although the consideration of SES at multiple levels (individual, household, and neighborhood) is an important strength of our study because each level may act independent of one another [84], it does not implicate any specific environmental stressors related to area poverty. In addition to the socioeconomic indicators we considered, other factors potentially may contribute to differential LINE-1 and Alu methylation such as prenatal exposures to persistent organic pollutants [27] and other chemicals [85], or other relevant biologic measures (e.g., BMI or cortisol levels [23]). Some of these effects have been assessed in previously published CHAMACOS studies $[26,27]$ and do not appear to be confounders in the current analyses. Although the homogeneity of the CHAMACOS population in the Salinas Valley, California is another potential limitation of our study, it is also a strength in that there is less likely to be uncontrolled confounding due to other factors. To make our findings more generalizable, additional studies in other ethnic and SES cohorts are warranted. It will be important to also further explore potential influence of maternal nutrition on associations between the socioeconomic status and DNA methylation.

\section{Conclusions}

We observed a modest but statistically significant association between neighborhood-level poverty and LINE-1 repeat element methylation in newborns, and the direction of this relationship appears to be modified by maternal diet during pregnancy. This finding implies that maternal diet may have a moderating effect on the association between neighborhood poverty and repeat element DNA methylation and that future epigenetic studies investigating the prenatal effects of social class should consider maternal diet as a potential moderator of neighborhood socioeconomic effects on epigenetics.

\section{Additional files}

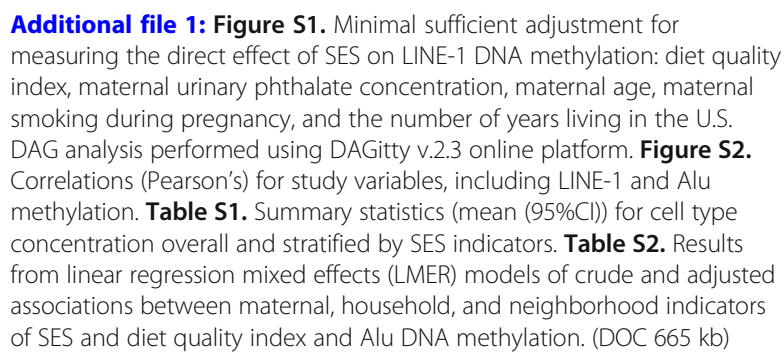

Additional file 1: Figure S1. Minimal sufficient adjustment for measuring the direct effect of SES on LINE-1 DNA methylation: diet quality index, maternal urinary phthalate concentration, maternal age, maternal smoking during pregnancy, and the number of years living in the U.S. DAG analysis performed using DAGitty v.2.3 online platform. Figure S2. Correlations (Pearson's) for study variables, including LINE-1 and Alu methylation. Table S1. Summary statistics (mean (95\%Cl)) for cell type concentration overall and stratified by SES indicators. Table S2. Results from linear regression mixed effects (LMER) models of crude and adjusted associations between maternal, household, and neighborhood indicators of SES and diet quality index and Alu DNA methylation. (DOC 665 kb)

\section{Abbreviations}

BMI: Body mass index; CHAMACOS: Center for Health Assessment of Mothers and Children of Salinas; DAG: Directed acyclic graph; DQI-P: Diet Quality Index for Pregnancy; FFQ: Food-frequency questionnaire; LINEs: Long interspersed nuclear elements; MBzP: Monobenzyl phthalate;

SES: Socioeconomic status; SINEs: Short interspersed nuclear elements

\section{Acknowledgements}

We are grateful to the numerous laboratory and field staff and participants of the CHAMACOS study for their contributions.

\section{Funding}

This publication was made possible by grants from the National Institute of Environmental Health Science (NIEHS) [P01 ES009605, R01 ES021369, R01 ES023067], from the US Environmental Protection Agency (EPA)[R82670901, and RD83451301], the National Institutes of Health (NIH) [UG3OD023356], Health Resources and Services Administration (HRSA) [T76MC00002], and a grant support from The JPB Foundation through the JPB Research Network on Toxic Stress, a project of the Center on the Developing Child at Harvard University.

Its contents are solely the responsibility of the authors and do not necessarily represent the official views of NIEHS, EPA, HRSA, or JPB Foundation. 


\section{Availability of data and materials}

The datasets generated during and/or analysed during the current study are not publicly available due to them containing information that could compromise research participant privacy/consent, but are available from the corresponding author on reasonable request.

\section{Authors' contributions}

EC analyzed and interpreted the participant data regarding the study finding and wrote the first draft of the manuscript. RG assisted with the conception and design of the data analysis and contributed to the writing and editing of the manuscript. KH assisted with the design of the data analysis, performed laboratory epigenetics analyses, and contributed to the writing and editing of the manuscript. $\mathrm{NH}$ assisted with the design of the data analysis and oversaw the epigenetics laboratory procedures, and contributed significantly to the writing and editing of the manuscript. BE designed and oversaw the collection of all aspects of the study data, assisted with the design of the data analysis, and contributed significantly to the writing and editing of the manuscript. All authors read and approved the final manuscript.

\section{Ethics approval and consent to participate}

Study protocols were approved by the University of California, Berkeley Committee for Protection of Human Subjects. Written informed consent was obtained from the mothers.

\section{Competing interests}

The authors declare that they have no competing interests.

\section{Publisher's Note}

Springer Nature remains neutral with regard to jurisdictional claims in published maps and institutional affiliations.

\section{Author details}

${ }^{1}$ Center for Environmental Research and Children's Health (CERCH), School of Public Health, University of California, Berkeley, CA, USA. 'Berkeley, USA. ${ }^{3}$ Richmond, USA.

\section{Received: 20 December 2017 Accepted: 25 April 2018}

\section{Published online: 08 May 2018}

\section{References}

1. Earnshaw VA, Rosenthal L, Lewis JB, Stasko EC, Tobin JN, Lewis $\Pi$, et al. Maternal experiences with everyday discrimination and infant birth weight: a test of mediators and moderators among young, urban women of color. Ann Behav Med. 2013;45:13-23.

2. Finch BK. Socioeconomic gradients and low birth-weight: empirical and policy considerations: socioeconomic gradients and low birth-weight. Health Serv Res. 2003:38:1819-42.

3. Nepomnyaschy L. Socioeconomic gradients in infant health across race and ethnicity. Matern Child Health J. 2009;13:720-31.

4. Silvestrin S, da Silva CH, Hirakata VN, AAS G, Silveira PP, Goldani MZ. Maternal education level and low birth weight: a meta-analysis. J Pediatr. 2013;89:339-45.

5. Cerdá M, Buka SL, Rich-Edwards JW. Neighborhood influences on the association between maternal age and birthweight: a multilevel investigation of age-related disparities in health. Soc Sci Med. 2008;66:2048-60.

6. Alhusen JL, Bower KM, Epstein E, Sharps P. Racial discrimination and adverse birth outcomes: an integrative review. J Midwifery Womens Health. 2016;61:707-20.

7. Blumenshine P, Egerter S, Barclay CJ, Cubbin C, Braveman PA. Socioeconomic disparities in adverse birth outcomes. Am J Prev Med. 2010;39:263-72.

8. Mutambudzi M, Meyer JD, Warren N, Reisine S. Effects of psychosocial characteristics of work on pregnancy outcomes: a critical review. Women Health. 2011:51:279-97.

9. Littleton HL, Bye K, Buck K, Amacker A. Psychosocial stress during pregnancy and perinatal outcomes: a meta-analytic review. J Psychosom Obstet Gynaecol. 2010;31:219-28.

10. Vuong B, Odero G, Rozbacher S, Stevenson M, Kereliuk SM, Pereira TJ, et al. Exposure to gestational diabetes mellitus induces neuroinflammation, derangement of hippocampal neurons, and cognitive changes in rat offspring. J Neuroinflammation. 2017;14:80.
11. Wallack L, Thornburg K. Developmental origins, epigenetics, and equity: moving upstream. Matern Child Health J. 2016:20:935-40.

12. Meaney MJ. Epigenetics and the biological definition of gene $x$ environment interactions. Child Dev. 2010;81:41-79.

13. NIH. Epigenomics Fact Sheet. Natl. Hum. Genome Res. Inst. NHGRI. 2016 [cited 2017 Sep 12]. Available from: https://www.genome.gov/27532724/ Epigenomics-Fact-Sheet

14. Notterman DA, Mitchell C. Epigenetics and understanding the impact of social determinants of health. Pediatr Clin N Am. 2015;62:1227-40.

15. Wilhelm-Benartzi CS, Houseman EA, Maccani MA, Poage GM, Koestler DC, Langevin SM, et al. In utero exposures, infant growth, and DNA methylation of repetitive elements and developmentally related genes in human placenta. Environ Health Perspect. 2011;120:296-302.

16. Wang L, Wang F, Guan J, Le J, Wu L, Zou J, et al. Relation between hypomethylation of long interspersed nucleotide elements and risk of neural tube defects. Am J Clin Nutr. 2010;91:1359-67.

17. Price EM, Cotton AM, Peñaherrera MS, McFadden DE, Kobor MS, Robinson W. Different measures of "genome-wide" DNA methylation exhibit unique properties in placental and somatic tissues. Epigenetics. 2012;7:652-63.

18. Hou L, Wang H, Sartori S, Gawron A, Lissowska J, Bollati V, et al. Blood leukocyte DNA hypomethylation and gastric cancer risk in a high-risk Polish population. Int J Cancer. 2010;127:1866-74.

19. Gao Y, Baccarelli A, Shu XO, Ji B-T, Yu K, Tarantini L, et al. Blood leukocyte Alu and LINE-1 methylation and gastric cancer risk in the Shanghai Women's Health Study. Br J Cancer. 2012;106:585-91.

20. Alexeeff SE, Baccarelli AA, Halonen J, Coull BA, Wright RO, Tarantini L, et al. Association between blood pressure and DNA methylation of retrotransposons and pro-inflammatory genes. Int J Epidemiol. 2013;42:270-80.

21. Rusiecki JA, Chen L, Srikantan V, Zhang L, Yan L, Polin ML, et al. DNA methylation in repetitive elements and post-traumatic stress disorder: a casecontrol study of US military service members. Epigenomics. 2012:4:29-40.

22. Nätt $D$, Thorsell A. Stress-induced transposon reactivation: a mediator or an estimator of allostatic load? Environ Epigenetics. 2016;2:dvw015.

23. Nätt D, Johansson I, Faresjö T, Ludvigsson J, Thorsell A. High cortisol in 5year-old children causes loss of DNA methylation in SINE retrotransposons: a possible role for ZNF263 in stress-related diseases. Clin Epigenetics. 2015 [cited 2018 Mar 7];7. Available from: http://www.clinicalepigeneticsjournal. com/content/7/1/91

24. Hunter RG, Gagnidze K, McEwen BS, Pfaff DW. Stress and the dynamic genome: steroids, epigenetics, and the transposome: fig. 1. Proc Natl Acad Sci 2015;112:6828-6833.

25. Bundo M, Toyoshima M, Okada Y, Akamatsu W, Ueda J, Nemoto-Miyauchi T, et al. Increased L1 retrotransposition in the neuronal genome in schizophrenia. Neuron. 2014;81:306-13.

26. Huen K, Calafat AM, Bradman A, Yousefi P, Eskenazi B, Holland N. Maternal phthalate exposure during pregnancy is associated with DNA methylation of LINE-1 and Alu repetitive elements in Mexican-American children. Environ Res. 2016;148:55-62.

27. Huen K, Yousefi P, Bradman A, Yan L, Harley KG, Kogut K, et al. Effects of age, sex, and persistent organic pollutants on DNA methylation in children: DNA methylation in children. Environ Mol Mutagen. 2014:55:209-22.

28. Watkins DJ, Wellenius GA, Butler RA, Bartell SM, Fletcher T, Kelsey KT. Associations between serum perfluoroalkyl acids and LINE-1 DNA methylation. Environ Int. 2014;63:71-6.

29. Bellavia A, Urch B, Speck M, Brook RD, Scott JA, Albetti B, et al. DNA hypomethylation, ambient particulate matter, and increased blood pressure: findings from controlled human exposure experiments. J Am Heart Assoc. 2013;2:e000212-2.

30. Lee $\mathrm{MH}$, Cho ER, Lim J, Jee SH. Association between serum persistent organic pollutants and DNA methylation in Korean adults. Environ Res. 2017;158:333-41.

31. Tajuddin SM, Amaral AFS, Fernández AF, Rodríguez-Rodero S, Rodríguez RM, Moore LE, et al. Genetic and Non-genetic Predictors of LINE-1 Methylation in Leukocyte DNA. Environ Health Perspect. 2013 [cited 2017 Nov 3]; Available from: http://ehp.niehs.nih.gov/1206068/

32. van Dijk SJ, Zhou J, Peters TJ, Buckley M, Sutcliffe B, Oytam Y, et al. Effect of prenatal DHA supplementation on the infant epigenome: results from a randomized controlled trial. Clin Epigenetics. 2016 [cited 2017 Aug 3];8. Available from: http://clinicalepigeneticsjournal.biomedcentral.com/articles/ 10.1186/s13148-016-0281-7

33. Devi S, Mukhopadhyay A, Dwarkanath P, Thomas T, Crasta J, Thomas A, et al. Combined vitamin B-12 and balanced protein-energy supplementation 
affect homocysteine remethylation in the methionine cycle in pregnant South Indian women of low vitamin B-12 status. J Nutr. 2017;147:1094-103.

34. Pauwels S, Ghosh M, Duca RC, Bekaert B, Freson K, Huybrechts I, et al. Dietary and supplemental maternal methyl-group donor intake and cord blood DNA methylation. Epigenetics. 2017;12:1-10.

35. Searles NS, Harvey C, Butler RA, Nelson HH, Farin FM, Longstreth WT, et al. LINE-1 DNA methylation, smoking and risk of Parkinson's disease. J Park Dis. 2012;2:303-8.

36. Ayarpadikannan S, Kim H-S. The impact of transposable elements in genome evolution and genetic instability and their implications in various diseases. Genomics Inform. 2014;12:98.

37. Su J, Shao X, Liu H, Liu S, Wu Q, Zhang Y. Genome-wide dynamic changes of DNA methylation of repetitive elements in human embryonic stem cells and fetal fibroblasts. Genomics. 2012;99:10-7.

38. Herbstman JB, Wang S, Perera FP, Lederman SA, Vishnevetsky J, Rundle AG, et al. Predictors and consequences of global DNA methylation in cord blood and at three years. PLoS One. 2013;8:e72824. El-Maarri O, editor

39. Marsit CJ, Maccani MA, Padbury JF, Lester BM. Placental 11-beta hydroxysteroid dehydrogenase methylation is associated with newborn growth and a measure of neurobehavioral outcome. PLoS One. 2012;7: e33794. Oudejans C, editor

40. King K, Murphy S, Hoyo C. Epigenetic regulation of newborns' imprinted genes related to gestational growth: patterning by parental race/ethnicity and maternal socioeconomic status. J Epidemiol Community Health. 2015;69:639-47.

41. King KE, Kane JB, Scarbrough P, Hoyo C, Murphy SK. Neighborhood and family environment of expectant mothers may influence prenatal programming of adult cancer risk: discussion and an illustrative DNA methylation example. Biodemography Soc Biol. 2016:62:87-104.

42. Javed $R$, Chen $W$, Lin F, Liang H. Infant's DNA methylation age at birth and epigenetic aging accelerators. Biomed Res Int. 2016;2016:1-10.

43. Krukowski RA, West DS, Harvey-Berino J, Elaine PT. Neighborhood impact on healthy food availability and pricing in food stores. J Community Health. 2010;35:315-20.

44. Laraia B. Proximity of supermarkets is positively associated with diet quality index for pregnancy. Prev Med. 2004;39:869-75.

45. Larson NI, Story MT, Nelson MC. Neighborhood environments. Am J Prev Med. 2009;36:74-81. e10

46. McLeod ER, Campbell KJ, Hesketh KD. Nutrition knowledge: a mediator between socioeconomic position and diet quality in Australian first-time mothers. J Am Diet Assoc. 2011:111:696-704.

47. Darmon N, Drewnowski A. Contribution of food prices and diet cost to socioeconomic disparities in diet quality and health: a systematic review and analysis. Nutr Rev. 2015;73:643-60.

48. Tarasuk V, McIntyre L, Li J. Low-income women's dietary intakes are sensitive to the depletion of household resources in one month. J Nutr. 2007;137:1980-7.

49. Pauwels S, Ghosh M, Duca RC, Bekaert B, Freson K, Huybrechts I, et al. Maternal intake of methyl-group donors affects DNA methylation of metabolic genes in infants. Clin Epigenetics [Internet]. 2017 [cited 2017 Aug 3];9. Available from: http://clinicalepigeneticsjournal.biomedcentral.com/ articles/10.1186/s13148-017-0321-y

50. McCullough LE, Miller EE, Mendez MA, Murtha AP, Murphy SK, Hoyo C. Maternal B vitamins: effects on offspring weight and DNA methylation at genomically imprinted domains. Clin Epigenetics [Internet]. 2016 [cited 2017 Aug 3];8. Available from: http://www.clinicalepigeneticsjournal. com/content $/ 8 / 1 / 8$

51. Haggarty P, Hoad G, Campbell DM, Horgan GW, Piyathilake C, McNeill G. Folate in pregnancy and imprinted gene and repeat element methylation in the offspring. Am J Clin Nutr. 2013;97:94-9.

52. Heijmans BT, Tobi EW, Stein AD, Putter H, Blauw GJ, Susser ES, et al. Persistent epigenetic differences associated with prenatal exposure to famine in humans. Proc Natl Acad Sci. 2008:105:17046-9.

53. Tobi EW, Lumey LH, Talens RP, Kremer D, Putter H, Stein AD, et al. DNA methylation differences after exposure to prenatal famine are common and timing- and sex-specific. Hum Mol Genet. 2009;18:4046-53.

54. Harley K, Eskenazi B. Time in the United States, social support and health behaviors during pregnancy among women of Mexican descent. Soc Sci Med. 2006;62:3048-61.

55. Block G, Woods M, Potosky A, Clifford C. Validation of a self-administered diet history questionnaire using multiple diet records. J Clin Epidemiol. 1990:43:1327-35.
56. Block G, Thompson FE, Hartman AM, Larkin FA, Guire KE. Comparison of two dietary questionnaires validated against multiple dietary records collected during a 1-year period. J Am Diet Assoc. 1992;92:686-93.

57. U.S. Department of Agriculture Agricultural Research Service. USDA National Nutrient Database for standard reference, release 13. Bethesda: U.S. Department of Agriculture; 1999.

58. Bodnar LM, Siega-Riz AM. A diet quality index for pregnancy detects variation in diet and differences by sociodemographic factors. Public Health Nutr. 2002;5:801-9.

59. Holland N, Furlong C, Bastaki M, Richter R, Bradman A, Huen K, et al. Paraoxonase polymorphisms, haplotypes, and enzyme activity in Latino mothers and newborns. Environ Health Perspect. 2006;114:985-91.

60. Yang AS. A simple method for estimating global DNA methylation using bisulfite PCR of repetitive DNA elements. Nucleic Acids Res. 2004:32:38e-38.

61. Royo $\mathrm{L}$, Hidalgo M, Ruiz A. Pyrosequencing protocol using a universal biotinylated primer for mutation detection and SNP genotyping. Nat Protoc 2007;2:1734-9.

62. Bollati V, Baccarelli A, Hou L, Bonzini M, Fustinoni S, Cavallo D, et al. Changes in DNA methylation patterns in subjects exposed to low-dose benzene. Cancer Res. 2007:67:876-80.

63. Michels KB, Harris HR, Barault L. Birthweight, maternal weight trajectories and global DNA methylation of LINE-1 repetitive elements. PLoS One. 2011 ; 6:e25254. Fugmann SD, editor

64. Burris HH, Rifas-Shiman SL, Baccarelli A, Tarantini L, Boeke CE, Kleinman K, et al. Associations of LINE-1 DNA methylation with preterm birth in a prospective cohort study. J Dev Orig Health Dis. 2012;3:173-81.

65. Boeke CE, Baccarelli A, Kleinman KP, Burris HH, Litonjua AA, Rifas-Shiman SL, et al. Gestational intake of methyl donors and global LINE-1 DNA methylation in maternal and cord blood: prospective results from a folatereplete population. Epigenetics. 2012;7:253-60.

66. Holland N, Huen K, Tran V, Street K, Nguyen B, Bradman A, et al. Urinary phthalate metabolites and biomarkers of oxidative stress in a MexicanAmerican cohort: variability in early and late pregnancy. Toxics. 2016;4:7.

67. Silva MJ, Samandar E, Preau JL, Reidy JA, Needham LL, Calafat AM. Quantification of 22 phthalate metabolites in human urine. J Chromatogr B Analyt Technol Biomed Life Sci. 2007;860:106-12.

68. Cardenas A, Allard C, Doyon M, Houseman EA, Bakulski KM, Perron P, et al. Validation of a DNA methylation reference panel for the estimation of nucleated cells types in cord blood. Epigenetics. 2016:11:773-9.

69. Bakulski KM, Feinberg JI, Andrews SV, Yang J, Brown S, L McKenney S, et al. DNA methylation of cord blood cell types: applications for mixed cell birth studies. Epigenetics. 2016;11:354-62.

70. Metcalfe A, Lail P, Ghali WA, Sauve RS. The association between neighbourhoods and adverse birth outcomes: a systematic review and meta-analysis of multi-level studies. Paediatr Perinat Epidemiol. 2011:25:236-45

71. Merlo J. Multilevel analytical approaches in social epidemiology: measures of health variation compared with traditional measures of association. J Epidemiol Community Health. 2003;57:550-2.

72. Olden $\mathrm{K}$, Olden HA, Lin Y-S. The role of the epigenome in translating neighborhood disadvantage into health disparities. Curr Environ Health Rep. 2015;2:163-70.

73. Bateson P, Gluckman P, Hanson M. The biology of developmental plasticity and the predictive adaptive response hypothesis: developmental plasticity and the PAR response. J Physiol. 2014;592:2357-68.

74. Davis EP, Sandman CA. The timing of prenatal exposure to maternal cortisol and psychosocial stress is associated with human infant cognitive development. Child Dev. 2010;81:131-48.

75. Oberlander TF, Weinberg J, Papsdorf M, Grunau R, Misri S, Devlin AM. Prenatal exposure to maternal depression, neonatal methylation of human glucocorticoid receptor gene (NR3C1) and infant cortisol stress responses. Epigenetics. 2008;3:97-106.

76. Lee J, Kalia V, Perera F, Herbstman J, Li T, Nie J, et al. Prenatal airborne polycyclic aromatic hydrocarbon exposure, LINE1 methylation and child development in a Chinese cohort. Environ Int. 2017:99:315-20.

77. Mazzio EA, Soliman KFA. Epigenetics and nutritional environmental signals. Integr Comp Biol. 2014;54:21-30.

78. Keita AD, Casazza K, Thomas O, Fernandez JR. Neighborhood-level disadvantage is associated with reduced dietary quality in children. J Am Diet Assoc. 2009;109:1612-6.

79. Stimpson JP, Nash AC, Ju H, Eschbach K. Neighborhood deprivation is associated with lower levels of serum carotenoids among adults 
participating in the Third National Health and Nutrition Examination Survey. J Am Diet Assoc. 2007;107:1895-902.

80. Kuczmarski MF, Cremer Sees A, Hotchkiss L, Cotugna N, Evans MK, Zonderman AB. Higher healthy eating Index-2005 scores associated with reduced symptoms of depression in an urban population: findings from the Healthy Aging in Neighborhoods of Diversity Across the Life Span (HANDLS) study. J Am Diet Assoc. 2010;110:383-9.

81. Molendijk M, Molero P, Ortuño Sánchez-Pedreño F, Van der Does W, Angel M-GM. Diet quality and depression risk: a systematic review and dose-response meta-analysis of prospective studies. J Affect Disord. 2018;226:346-54.

82. Marx W, Moseley G, Berk M, Jacka F. Nutritional psychiatry: the present state of the evidence. Proc Nutr Soc. 2017:1-10.

83. Kazmi N, Gaunt TR, Relton C, Micali N. Maternal eating disorders affect offspring cord blood DNA methylation: a prospective study. Clin Epigenetics [Internet]. 2017 [cited 2017 Nov 9];9. Available from: http://clinicalepigeneticsjournal. biomedcentral.com/articles/10.1186/s13148-017-0418-3

84. Ellen IG, Mijanovich T, Dillman K-N. Neighborhood effects on health: exploring the links and assessing the evidence. J Urban Aff. 2001;23:391-408.

85. Hossain K, Suzuki T, Hasibuzzaman MM, Islam MS, Rahman A, Paul SK, et al, Chronic exposure to arsenic, LINE-1 hypomethylation, and blood pressure: a cross-sectional study in Bangladesh. Environ Health [Internet]. 2017 [cited 2018 Mar 14];16. Available from: http://ehjournal.biomedcentral.com/ articles/10.1186/s12940-017-0231-7

Ready to submit your research? Choose BMC and benefit from:

- fast, convenient online submission

- thorough peer review by experienced researchers in your field

- rapid publication on acceptance

- support for research data, including large and complex data types

- gold Open Access which fosters wider collaboration and increased citations

- maximum visibility for your research: over $100 \mathrm{M}$ website views per year

At BMC, research is always in progress.

Learn more biomedcentral.com/submissions 